\title{
UNIDADES FRASEOLÓGICAS COM ZOÔNIMOS: UM OLHAR PELA JANELA DA INFLUÊNCIA CULTURAL
}

Phraseological Units with Zoonyms: A Look through the Window of the Cultural Influence

\section{Unidades fraseológicas con zoónimos: una}

mirada por la ventana de la influencia cultural

\author{
Rosana Budny* \\ Universidade Federal da Grande Dourados, \\ Faculdade de Comunicação, Artes e Letras, Dourados, MS, Brasil
}

\begin{abstract}
Resumo: Este artigo argumenta sobre a influência dos aspectos culturais nas unidades fraseológicas com zoônimos (UFz), expressões que levam um zoônimo em sua composição. As UFz refletem a história e a cultura do povo que as utiliza e nelas estão inseridas expressões idiomáticas como da língua portuguesa do tipo ser um bagre ensaboado (em inglês to be as slippery as an eel). Os pressupostos teóricos são os da Fraseologia com Manca (2008), Hall ([1976] 1989), Malinowski (1922, 1923, 1935), Corpas Pastor (1996), Corpas Pastor e Mena Martínez (2004), Lakoff e Johnson (1980, 1987, 1990), etc. Os aspectos culturais influenciam as unidades fraseológicas e facultam o aparecimento de coincidências interlinguísticas, janelas culturais, que fomentam a dimensão universal, e têm nas metáforas conceptuais a origem de certos fraseologismos. A metodologia apresenta algumas UFz em português com correspondências funcionais em inglês.
\end{abstract}

Palavras-chave: Fraseologia. Unidades fraseológicas. Zoônimos. Cultura. Interfraseologia.

\begin{abstract}
This paper discuss about the influence of the cultural aspects on the phraseological units with zoonyms (PHUz), expressions that carry a zoonym in their composition. The PHUz reflect the history and culture of the people who use them, and they include idiomatic expressions from Brazilian Portuguese language such as ser um bagre ensaboado (to be as slippery as an eel). We mobilize some theoretical foundations about Phraseology, including Manca (2008), Hall ([1976] 1989), Malinowski (1922, 1923, 1935), Corpas Pastor (1996), Corpas Pastor and Mena Martínez (2004), Lakoff and Johnson (1980, 1987, 1990), etc. Cultural aspects influence on the phraseological units and allow the appearance of interlinguistic coincidences, cultural windows that foment the universal dimension, and possess, in the conceptual metaphors, the origin of certain phraseologysms. The methodology presents some PHUz in Brazilian Portuguese with functional correspondences in English.
\end{abstract}

Keywords: Phraseology. Phraseological units. Zoonyms. Culture. Interphraseology.

Resumen: Este artículo hace argumento sobre la influencia de los aspectos culturales en unidades fraseológicas con zoónimos (UFz), expresiones que llevan un zoónimo en su composición. Las UFz reflejan la historia y la cultura del pueblo que las utiliza, y en ellas están insertadas expresiones idiomáticas, como de la lengua portuguesa, del tipo ser um bagre ensaboado (en inglés, to be as slippery as an eel). Los supuestos teóricos son de la Fraseología, con Manca (2008), Hall ([1976] 1989), Malinowski (1922, 1923, 1935), Corpas Pastor (1996), Corpas Pastor y Mena Martínez (2004), Lakoff y Johnson (1980, 1987, 1990),

* Pós-doutoranda do Programa de Pós-Graduação em Estudos de Linguagens da Universidade Federal do Mato Grosso do Sul. Docente do Curso de Letras Português- Inglês da Faculdade de Comunicação, Artes e Letras da Universidade Federal da Grande Dourados, Dourados, MS. ORCID: https://orcid.org/0000-0003-4105-1202. E-mail: ro.budny@uol.com.br. 
entre otros. Aspectos culturales influencian las unidades fraseológicas y facultan el aparecimiento de coincidencias interlingüísticas, ventanas culturales que fomentan la dimensión universal y tienen en las metáforas conceptuales el origen de algunos fraseologismos. La metodología presenta UFz en portugués con correspondencias funcionales en inglés.

Palabras clave: Fraseología. Unidades fraseológicas con zoónimos. Influencia cultural. Inter fraseología.

\section{INTRODUÇÃO}

Algumas características apresentadas nas unidades fraseológicas com zoônimos podem ser interpretadas pela janela da influência cultural sofrida por esses fraseologismos no contexto das comunidades de fala. Traços da cultura de origem, de anos ou séculos, podem ser percebidos nos significados que veiculam.

Assim, as unidades fraseológicas com zoônimos (UFz) refletem a vida, o comportamento, a história e a cultura do povo que as utiliza, estabelecendo um relacionamento estreito com o passado cultural, com o ambiente geográfico e os costumes desse povo. São influências que se revelam nos fraseologismos veiculados pela língua, desvendando características que emergem de janelas culturais, e dão a conhecer possíveis contextos, o que "facilita", de certa forma, o entendimento. Um exemplo é o de expressões idiomáticas inseridas nas unidades fraseológicas (UFs) como as usadas em nosso falar diário da língua portuguesa, do tipo ser um bagre ensaboado - referência a uma pessoa que demonstra esperteza ou que consegue se sair de perguntas com respostas evasivas. Na língua inglesa poderíamos dar a seguinte equivalência funcional: to be as slippery as an eel - pessoa que disfarça e não responde a uma pergunta adequadamente. Nessa comparação as palavras usadas na língua portuguesa não são as mesmas usadas na língua inglesa, no entanto, o significado que elas veiculam é correspondente; isso acontece porque a equivalência ou correspondência nas unidades fraseológicas, em geral, não é entendida literalmente, mas, sim, figuradamente.

Podemos afirmar que as expressões fraseológicas zoonímicas acabam por "expor" a cultura dessas comunidades, de forma lúdica e colorida, trazendo à tona cenas de histórias vividas e comportamentos assumidos. E as expressões figuradas como provérbios, expressões idiomáticas, combinações, colocações, e ditos, em geral, são decodificadores naturais para o entendimento de crenças, costumes e convenções sociais; convenções que norteiam os usos das línguas e capacitam o falante a expressar e a entender pensamentos, emoções e visões de mundo como usuário daquele sistema de comunicação.

A crescente conscientização acerca da importância dos fraseologismos e de suas especificidades no entendimento das diversas línguas tem levado ao aumento de pesquisas sobre o tema e feito avanços na área (MANCA, 2015; CORPAS PASTOR; ORTIZ ALVAREZ, 2017; PAMIES-BERTRÁN, 2017). Nos tópicos a seguir expomos alguns estudos em torno da cultura e de sua influência na compreensão dos fraseologismos, com destaque para o fato de que o aspecto cultural desenha a estrutura conceptual das línguas nos diversos contextos de interação. 
Manca (2008), em seu estudo From phraseology to culture - qualifying adjectives in the language of tourism, descreve as unidades fraseológicas associadas aos adjetivos na linguagem do turismo em que esses foram separados em campos semânticos. A partir dos campos semânticos foram identificados os perfis colocacionais. Foram usados corpora do agroturismo para se comparar e contrastar as línguas italiana e inglesa. Na análise, a autora utilizou as teorias de Sinclair (1991) sobre a influência dos contextos e dos registros na escolha das línguas; as teorias de Hall $(1976,1989)$ sobre a cultura de contextos, que enfatiza a quantia (alta e baixa) de informação contextual e linguística necessária para a transmissão de significados nas diferentes culturas, assim como os modos diferentes de interação. A análise mostra uma incidência altamente fraseológica na linguagem do turismo e também diferenças e similaridades nas orientações culturais e no sistema de línguas do italiano em relação ao sistema do inglês.

Para Manca (2008, p. 371), a cultura é um conceito multifacetado que envolve música, literatura e outras artes, bem como um conjunto de ideias, crenças e modos de comportamento associados à organização de certo grupo de pessoas. Tal conceito objetiva entender a influência da cultura na língua de um povo. Acrescentamos a concepção de Katan (2004, p. 26) para quem a cultura não é necessariamente um produto, mas algo internalizado, coletivo e adquirido, muito mais do que aprendido. Trata-se de uma aquisição natural dos valores e comportamentos por meio do observar e do 'ouvir' diários. A cultura adquirida passa a interferir no modo de interpretar o conteúdo linguístico produzido no bojo do contexto onde a ação ou o texto acontecem. Para o desenvolvimento deste artigo assumimos tanto o conceito de Manca quanto o de Katan no que se refere à cultura.

A teoria de contexto foi primeiramente desenvolvida por Malinowski (1922, 1923, 1935), citado por Manca (2008, p. 371). O autor afirma:

\begin{abstract}
A língua é enraizada na realidade da cultura, da vida tribal e costumes do povo, e [...] não pode ser explicada sem a referência constante desses contextos amplos de enunciação verbal [...] uma enunciação se torna inteligível quando é situada em seu contexto de situação (MALINOWSKI, 1923, p. 305, tradução nossa). ${ }^{1}$
\end{abstract}

Dessa forma, o contexto está imbricado quando se tenta interpretar o princípio fraseológico de uma determinada expressão no discurso. O linguista J. R. Firth (1950, p. 182) foi igualmente influenciado pelo 'contexto de situação' de seu colega Malinowski, e acrescenta ao conceito a ideia do conjunto cultural por inteiro no ato de fala, e não somente o contexto de atividade humana. Firth reforça a relevância do contexto na identificação do significado de uma enunciação.

\footnotetext{
${ }^{1}$ Language is essentially rooted in the reality of the culture, the tribal life and customs of the people, and [...] It cannot be explained without constant reference to these broader contexts of verbal utterance [...] an utterance becomes intelligible when it is placed within its context of situation. (MALINOWSKI, 1923, p. 305, apud MANCA, 2008, p. 371)
} 
Para Sinclair (1996, p. 71), o contexto é estritamente linguístico em que as palavras produzem relações de significados no entorno com outras palavras. Segundo o autor (SINCLAIR, 1991, 1996), a língua funciona seguindo dois princípios: o princípio da livre escolha e o princípio fraseológico. No entanto, para o autor o princípio fraseológico é o mais produtivo, pois põe à disposição do falante um grande número de frases préfabricadas. A existência de tais frases se deve à ocorrência constante de situações similares dos afazeres humanos e a tendência ao princípio do menor esforço. Na base da tendência fraseológica está o princípio fraseológico em que as palavras tendem a se juntar e combinar, construindo, assim, significados. As colocações podem muito bem ilustrar seu argumento.

Hall (1989 [1976]) percebe a relação com o contexto como sendo "a quantia de informação que se pode esperar que a outra pessoa possua sobre um dado assunto" (HALL, 1989 [1976], p. 61). Na visão de Hall, o contexto de cultura afeta a vida humana, o comportamento das pessoas, seu modo de pensar, de expressar emoções e até o de construir suas cidades. (HALL, 1989 [1976], p.14).

$\mathrm{O}$ modo como as pessoas, de diferentes culturas interagem afeta a construção e a transmissão de significados em seus contextos (KATAN, 2004). Assim, podemos depreender das visões expressas por tais autores que as combinações fraseológicas desempenham funções pragmáticas, retóricas e textuais e que as palavras possuem certos aspectos prosódicos que são típicos de determinada língua.

Se o contexto de cultura, com suas crenças, costumes, comportamentos e rituais influencia a língua e constitui a identidade cultural de um grupo de pessoas, então "é crucial que a fraseologia e os aspectos culturais não sejam desprezados na análise da construção de significado" (MANCA, 2008, p. 383)2. Nesse sentido, não basta o conhecimento linguístico para o reconhecimento dos significados no uso da língua, na medida em que o conhecimento cultural, a consciência do contexto sociocultural e suas convenções estão atrelados a essas formas; consequentemente, a cultura exerce papel relevante na interpretação e na produção de sentido das ideias veiculadas pela língua.

\section{DA INTERNACIONALIZAÇÃO PARA A GLOBALIZAÇÃO FRASEOLÓGICA - JANELAS PARA ENTENDIMENTO DO CONTEXTO INTERNACIONAL}

Com o avanço dos estudos em fraseologia é cada vez mais frequente encontrarmos estudos contrastivos entre as línguas e observarmos análises que apresentam, quase sempre, as semelhanças e as diferenças entre as unidades fraseológicas de vários pares de línguas. A interação entre cultura e fundo ideológico das línguas acaba por influenciar as formas e as preferências linguísticas dos diferentes povos.

Um estudo das pesquisadoras Corpas Pastor e Mena Martínez, apresentado no artigo La globalización de la fraseología como convergência cultural (2004, p.9), argumenta sobre uma possível globalização fraseológica que estaria acontecendo em

$2[\ldots]$ it is crucial that phraseology and cultural features are not separated in the analysis of meaning. (MANCA, 2008, p. 383). 
virtude de fatores como convergência cultural, entre outros. Conforme as autoras, a internacionalização da fraseologia como campo de estudo e como disciplina pode ser considerada um fato consumado.

Para o propósito do estudo citado, as autoras $(2004,10)$ definem fraseologia, com base em Corpas Pastor (1996), como

\begin{abstract}
inventário de UFs, ou seja, combinações estáveis formadas por pelo menos duas palavras gráficas e cujo limite superior se situa ao nível da oração completa (oração aqui levando-se em consideração o fato que temos os provérbios incluídos na família das Unidades Fraseológicas e que são considerados enunciados completos, ou seja, uma oração), caracterizadas por sua frequente coaparição e institucionalização na língua, e pelos diversos graus de idiomaticidade e variação que podem apresentar (CORPAS PASTOR, 1996, p. 269, tradução nossa) ${ }^{3}$
\end{abstract}

As combinações estáveis levam a uma institucionalização da língua que veiculam, pois, a globalização cultural enquanto fenômeno linguístico, é definida pelo valor cultural que a língua em questão agrega. Para as autoras, um exemplo de globalização cultural seria a homogeneização que se observa na reprodução de vários símbolos e atitudes culturais, verificados, por exemplo, nos hábitos alimentícios (Coca-Cola no mundo), na música, na moda e na língua.

No panorama apresentado, as possibilidades para a produção da internacionalização das UFs, dar-se-iam por meio de uma interculturalidade prototípica no terreno da linguística, constituindo fator propício para embasar certas convergências, uma globalização fraseológica, fenômeno facilmente recorrente em continente europeu, por exemplo, devido à proximidade desses países e às fronteiras abertas entre eles. O aspecto destacado converge para o uso real das UFs com foco nas coincidências fraseológicas dos fenômenos linguísticos como processo vivo, atual e ativo transpassado por muitos fatores. Corpas Pastor e Mena Martínez $(2004,10)$ argumentam que já se percebe uma concreta generalização da fraseologia no continente europeu. O fenômeno linguístico, segundo as autoras, possui características peculiares de identidade singular, posto que os sistemas fraseológicos de muitas línguas

\footnotetext{
se nutrem de fontes comuns, sendo que um fenômeno de internacionalização poderia supor um reconhecimento do passado e um maior entendimento entre os povos, fundamentado no ressurgir de formas compartilhadas e na apreciação consciente de possuir as mesmas raízes". (CORPAS PASTOR; MENA MARTÍNEZ, 2004, p. 14, tradução nossa) ${ }^{4}$.
}

\footnotetext{
${ }^{3}[\ldots]$ inventario de unidades fraseológicas (UFs), esto es, combinaciones estables formadas ao menos por dos palavras gráficas y cuyo límite superior se sitúa em el nivel de la oración compuesta, las cuales se caracterizan por su alta frecuencia de (co)aparición y su institucionalización em la lengua, así como los diversos grados de idiomaticidade y variación que éstas pueden presentar. (CORPAS PASTOR, 1996, p.269).

${ }^{4} \mathrm{Y}$ es que los sistemas fraseológicos de muchas lenguas se nutren de fuentes comunes, por lo que un fenómeno de internacionalización podría suponer un reconocimiento del pasado y un mayor entendimiento entre los pueblos, fundamentado em el resurgir de formas compartidas y em la apreciación consciente de poseer las mismas raíces. (CORPAS PASTOR; MENA MARTÍNEZ, 2004, p. 14).
} 
A interdependência de que se nutre a globalização linguística, com seus traços assimétricos, pode contribuir para uma uniformização fraseológica, segundo as autoras, e oferecer elementos a favor da homogeneização. Por um lado, encontram-se os fatores positivos que fundamentam as 'bases comuns' existentes nas línguas; por outro, fatores negativos, desencadeados pela imposição de componentes específicos da própria cultura. Os dois focos, ainda que opostos, podem sustentar os pilares de uma uniformização da fraseologia.

Os sistemas fraseológicos apresentam aspectos linguísticos, cognitivos e culturais que coincidem em várias línguas e culturas. As 'coincidências interlinguísticas e interfraseológicas' resultantes se dão graças aos universais linguísticos, assim nomeados não porque sejam "universais", comuns a "todas" as línguas, mas por que apresentam símbolos, metáforas conceptuais e outros elementos - como fontes comuns da cultura greco-latina para algumas línguas. Há também os contatos linguísticos que ocorrem pelos movimentos migratórios, tal como assinala Rosa Rabadán (2000, p.1):

\begin{abstract}
Os movimentos de internacionalização influenciam a uniformização fraseológica no âmbito das políticas europeias para a educação e formação universitária sendo um dos fatores que trazem consequências para a comunicação interlinguística e intercultural. Pode-se observar certa uniformização linguística e textual entre as diferentes línguas por meio de universais linguísticos (RABADÁN, 2000, p. 1, tradução nossa).
\end{abstract}

Os universais linguísticos apresentam traços, propriedades e fenômenos de caráter universal, comuns a muitas línguas e que "são um germe importante para o desenvolvimento da homogeneização ou universalização das UFs" (CORPAS PASTOR; MENA MARTÍNEZ, 2004, p.16). São fatores que têm levado pesquisadores a investigar coincidências entre os diferentes sistemas fraseológicos. Corpas Pastor (2000, p. 484) chama a atenção para a existência de semelhanças e paralelismos entre línguas, como, por exemplo, o espanhol e o inglês.

Nessas duas línguas, os paralelismos se organizam em torno de três grandes esferas, divididas pela autora em colocações, locuções e enunciados fraseológicos, que se aplicam igualmente às línguas romances, germânicas e semíticas. As colocações, UFs formadas por duas unidades léxicas em relação sintática que não constituem, por si mesmas, atos de fala nem enunciados; por sua fixação pela norma, apresentam restrições de combinação estabelecidas pelo uso, geralmente de base semântica. (CORPAS PASTOR, 1996, p. 66). Exemplo: desempenhar um papel - to play a role. As locuções, segundo Gläser (1986), pertencem ao centro do sistema fraseológico e demonstram uma unidade prototípica. Não constituem enunciados completos e possuem maior grau de estabilidade e consolidação. Nas locuções podemos citar expressões idiomáticas como, por exemplo, estar em palpos de aranha - em inglês poder-se-ia apresentar um correspondente fraseológico do tipo to have (hold) a wolf by the ears, que demonstra esse paralelismo. Essas unidades se caracterizam por formar uma unidade de significado. Os enunciados fraseológicos, caracterizados por enunciados completos que constituem atos de fala e gozam de autonomia semântica e às vezes autonomia textual. São enunciados fraseológicos as

\footnotetext{
${ }^{5}$ El continuo contacto y convivencia más o menos soterrada de distintas lenguas en un mismo espacio geográfico y mediático ayuda al proceso de adaptación /transferencia de procedimientos estructurales en las lenguas en contacto.
} 
parêmias e as fórmulas de rotina, que podemos exemplificar com as parêmias Burro velho não pega passo - com seu correspondente fraseológico You can't teach an old dog new tricks. As parêmias são enunciados fraseológicos que possuem autonomia textual e um grau alto de generalização. Possuem caráter referencial.

Nos estudos recentes da fraseologia tem-se observado que as coincidências interlinguísticas e os paralelismos fomentam a dimensão universal. Dobrovolskij (1998, 1992, apud CORPAS PASTOR; MENA MARTÍNEZ, 2004, p. 18) fala da existência dos universais fraseológicos. $\mathrm{O}$ autor divide os universais fraseológicos em três grupos: universais fraseológicos conceituais, não determinados linguisticamente; universais léxico-fraseológicos; universais fraseológicos propriamente ditos. A seguir identificamos cada um deles.

a) Universais fraseológicos conceituais - neles reside a orientação semântica dos aspectos referenciais e associativos da nominação fraseológica sobre o homem.

b) Universais léxico-fraseológicos - neles ubicam fenômenos do sistema interno das línguas como a polissemia, a homonímia, a sinonímia e antonímia.

c) Universais fraseológicos - neles abrigam leis que regulam os sistemas fraseológicos como a existência de variantes e modificações fraseológicas, as palavras diacríticas, os diferentes graus de idiomaticidade.

Os universais fraseológicos são ideais para o desenvolvimento da homogeneização fraseológica por representarem o primeiro depósito simétrico das línguas (CORPAS PASTOR; MENA MARTÍNEZ, 2004, p.18); neles metáforas conceptuais e símbolos de bases comuns fazem as coincidências fraseológicas.

\section{AS METÁFORAS CONCEPTUAIS COMO FONTES DE COINCIDÊNCIAS FRASEOLÓGICAS}

Na dimensão universal alcançada pelos fenômenos fraseológicos estão as metáforas conceptuais imbricadas na origem de certos fraseologismos.

As metáforas conceptuais caracterizam-se por serem generalizações, estruturas abstratas, modelos cognitivos que permitem agrupar expressões metafóricas distintas ao redor de uma origem comum - que empresta seus conceitos para um destino comum. (LAKOFF; JOHNSON, 1980, 1987, 1990, apud CORPAS PASTOR; MENA MARTÍNEZ, 2004, p. 18).

Os modelos metafóricos (metáforas e metonímias) se fundamentam na habilidade comum dos seres humanos, no seu modo de conceituar o mundo com a experiência corporal direta (cf. JOHNSON, 1987), constituindo-se em condições universais prévias. As metáforas e metonímias permitem estabelecer relações entre o significado literal e o figurativo ${ }^{6}$, que se convertem nas entidades independentes de cada cultura. Dado seu

\footnotetext{
${ }^{6}$ Piquer-Pirez e Boers (2019) bem exemplificam a questão do sentido literal para o sentido figurado ao dizer que "Cuando le pedimos a un alumno que intente explicar por qué llamamos cabecera a la parte superior de una cama, estamos propiciando que busque la relación de este sentido figurado con el significado literal de cabeza y que pueda compararlo con otros usos lingüísticos como el hecho de que, por analogía, a la parte inferior se le denomine los pies de la cama. Se ha demostrado que la capacidad para establecer este tipo de relaciones entre los distintos significados de un término está presente desde edad muy tempranas [...]. Si el lenguaje es un amplio repertorio de unidades simbólicas con significado
} 
caráter universal, tais ferramentas cognitivas acabam por ser fontes de coincidências linguísticas e fraseológicas, projetando regularidades em sua semântica.

Para entendermos a existência de regularidades na semântica das unidades fraseológicas, e entre elas as expressões idiomáticas, tomamos como base Casadei (1996) que explica as teorias cognitivas da metáfora. Ela organiza as expressões idiomáticas em quatro grandes divisões: o espaço, o movimento e a força, o corpo, e o domínio cultural. A autora argumenta que, com base no enfoque cognitivo, se pode afirmar que as estruturas metafóricas subjacentes nas expressões idiomáticas estão enraizadas e motivadas por aspectos da experiência extralinguística, em especial os aspectos sensoriais e corporais. (CASADEI, 1996, p. 393, apud CORPAS PASTOR; MENA MARTÍNEZ, 2004, p. 20)

Relativamente aos aspectos culturais, os símbolos são os mais relevantes, assim também são os fatos históricos, e outros fenômenos próprios das manifestações culturais.

O símbolo é um signo que não é completamente arbitrário e possui como condição prévia a reinterpretação semântica. Dessa forma, podemos exemplificar com a palavra negro, que adquire função simbólica, com significado figurativo, quando aparece em uma expressão do tipo ter um dia negro em que negro tem o significado de mal (CORPAS PASTOR; MENA MARTÍNEZ, 2004, p. 22). Para Dobrovolskij y Piirainen (1997), existem os símbolos da cultura e os símbolos da língua enquanto sistema; os primeiros estão motivados somente diacronicamente enquanto que os segundos podem ser compreendidos sincronicamente.

Nas línguas majoritárias há estudos que analisam a presença de um ou de vários âmbitos simbólicos nas UFs. Os mais investigados são os aspectos cromáticos e os numéricos juntamente com o dos animais, objeto do nosso estudo. Um desses trabalhos que investiga nove línguas é o de Dobrovolskij y Piirainen (2000). Os autores objetivaram uma análise interlinguística das línguas nos aspectos da simbologia animal, cromática e numérica. Com relação à simbologia animal, observaram grande recorrência desse símbolo na fraseologia das várias línguas. O lobo, por exemplo, com os significados de perigo, agressividade e fome aparece nos exemplos de várias fraseologias. Outros animais como a águia, o corvo, o asno e o galo apresentam aspectos metafóricos que favorecem a geração de UFs nas línguas avaliadas.

Além dos símbolos está a herança cultural de cada língua. Para Corpas Pastor e Mena Martínez (2004, p. 25), o desenvolvimento cultural de um povo "está condicionado por uma série de feitos das mais diversas naturezas, sucessos históricos, crenças, vivências e inclusive as próprias manifestações que se produzem nas diferentes esferas que abarcam a cultura"7 [tradução nossa] e o desenvolvimento cultural se reflete na língua e na formação de expressões que veiculam essas vivências.

y relacionadas entre sí, se debe reconocer la importancia [...] de unidades léxicas más complejas (como, por ejemplo, las expresiones idiomáticas o las colocaciones, entre otras). [...] la importancia del aprendizaje de unidades léxicas se pone de manifiesto que no se trata solo de aprender miles de palavras y sus distintos significados sino también de percibir las combinaciones y relaciones léxicas.

${ }^{7}$ El desarrollo cultural de un pueblo está condicionado por una serie de hechos de variada naturaleza, sucesos históricos, creencias, vivencias e incluso por las propias manifestaciones que se producen en las distintas esferas que abarca la cultura. 
Entre os elementos que afetam diretamente a formação das UFs estão os componentes que participam de uma forma ou de outra na origem. As autoras (OP.CIT.) apontam principalmente os aspectos da herança cultural europeia, influenciada pelos clássicos greco-romanos, pelas traduções de grandes obras e pelo legado da literatura universal, bem como da bíblia. Nesse contexto se encontram as unidades fraseológicas comuns às línguas europeias que se originam das mesmas fontes culturais e, dessa forma, coincidem, ainda que parcialmente, no conteúdo. Os chamados europeísmos vêm da observação do mundo que os rodeia, o comportamento dos seres vivos, os fenômenos naturais, os costumes e as crenças. A bíblia, por sua vez, tanto o antigo testamento quanto o novo testamento, tem servido de inspiração para os povos cristãos na formação de UFs e estas, incorrendo em correspondências interlinguísticas.

Para atestar correspondências interlinguísticas e interfraseológicas, considera-se a análise contrastiva entre línguas um método útil, especialmente na Paremiologia, para se observar as relações entre os refrãos de culturas e línguas diferentes que, muitas vezes, apresentam semelhanças relevantes (CORPAS PASTOR; MENA MARTÍNEZ, 2004; PIÑEL, 1999). Há coincidências entre o espanhol e o alemão (culturas aparentemente tão diferentes), com a parêmia de noche todos los gatos son pardos com seu correspondente em alemão in der Nacht sind alle Katzen grau. Há muitos exemplos também entre o português e o inglês, como a parêmia uma andorinha só não faz verão e em inglês one swallow doesn't make summer.

O processo de difusão desse caudal fraseológico se dá em função da mobilidade entre os povos, dos contatos intralinguísticos multiétnicos e da influência dos meios de comunicação, por exemplo, do cinema, assim como do impacto das redes tecnológicas mundiais.

Com culturas compartilhadas, as transferências entre as línguas constituem fonte inesgotável de criação fraseológica, sendo aspectos culturais tão ambivalentes que podem fomentar coincidências fraseológicas ou divergir das UFs. Nos aspectos culturais se encontram sinais que caracterizam a identidade nacional e cultural das línguas, conforme citação a seguir:

\begin{abstract}
As divergências interfraseológicas refletidas pelos estudos contrastivos podem ser fruto da existência de raízes culturais distantes e diferentes ou simplesmente resultado de uma série de casualidades linguísticas. Há graus relevantes de separação em que se podem encontrar significados antônimos em diversas línguas e culturas sob um mesmo símbolo (CORPAS PASTOR; MENA MARTÍNEZ, 2004, p. 34, tradução nossa) ${ }^{8}$
\end{abstract}

O exemplo da coruja ilustra o argumento de possíveis divergências fraseológicas, se na cultura ocidental ela manifesta uma função simbólica de sabedoria, conhecimento, em outras línguas europeias pode denotar tanto sabedoria quanto estupidez (cf. DOBROVOLSKIJ; PIIRAINEN, 2000): as wise as an owl (inglês), zo dom als een uil

\footnotetext{
${ }^{8}$ Las divergencias interfraseológicas reflejadas en los estudios contrastivos pueden ser fruto de la existencia de raíces culturales distantes y diferentes o simplemente ser el resultado de una serie de casualidades lingüísticas. Tal es el grado de separación que en ocasiones pueden encontrarse significados antónimos en diversas lenguas y culturas bajo un mismo símbolo. (CORPAS PASTOR; MENA MARTÍNEZ, 2004, p. 34)
} 
(holandês - tão estúpido quanto uma coruja). Nazarenko e Iñesta (1998, p.101) chamam de zoomorfismo o uso metafórico e alegórico do nome de um animal para caracterizar uma conduta, ou certo traço de caráter do ser humano.

É comum encontrarmos expressões em que a simbologia animal pode gerar divergências fraseológicas. Para o linguista polaco T.P. Krzeszowski (1990, p.150): “as palavras têm uma tendência a serem axiologicamente carregadas de boas ou más conotações em proporção ao grau do fator humano associado a elas". O grau de fator humano que se associa a qualidades morais e físicas é alto e, portanto, os zoônimos estão carregados desses valores.

Com o estudo apresentado, é possível intuirmos que o papel das metáforas conceituais na criação e interpretação das UFs é a causa de muitas coincidências fraseológicas nas expressões figurativas de línguas distantes. Nessas destacamos os símbolos dos animais que se refletem nas fraseologias de várias línguas com a mesma função simbólica. A "conservação daquelas unidades com traços de especificidade cultural e nacional depende do uso que os falantes fazem dessas unidades e das políticas educativas e linguísticas dos governos nacionais e regionais (CORPAS PASTOR; MENA MARTÍNEZ, 2004, p. 37, tradução nossa) ${ }^{9}$.

A compreensão dos aspectos universais e compartilhados poderá aumentar a compreensão e a tolerância entre os povos, assim como favorecer o entendimento linguístico.

\section{ANÁLISE DE ALGUNS DADOS ENCONTRADOS EM NOSSA PESQUISA - FOCO NA INFLUÊNCIA CULTURAL}

Para maior entendimento das unidades fraseológicas, temos feito estudo no sentido de buscar equivalentes tradutórios para as UFz. No âmbito de um projeto de pósdoutoramento, com o título Glossário Português-Inglês de fraseologia zoonímica criação de um banco de dados e protótipo lexicográfico, pretendemos a construção de um glossário dessa natureza.

As janelas culturais que se abrem para o entendimento de uma expressão admitem múltiplas interpretações no discurso de uma dada comunidade linguística. Palavras ou expressões facultam ao falante poder selecionar, entre os muitos traços constitutivos, um que o torna apto a exprimir e linearizar determinado sentido num dado contexto. Sabemos que as unidades lexicais não carregam apenas significados denotacionais ou referentes do mundo extralinguístico, mas apresentam amplo conjunto de aspectos prototípicos disponíveis no universo lexicalizado da língua. Há campos semânticos geradores de unidades fraseológicas, em que os mecanismos icônicos, fontes dessas expressões, desaguam em domínios meta onde "os primeiros servem para motivação metafórica" (VILELA, 2003, p.1). São numerosos os modelos icônicos, e, neste caso, tratamos do modelo icônico ANIMAL (LAKOFF; JOHNSON, 1980) ou a chamada metáfora

\footnotetext{
${ }^{9}$ La conservación de aquellas unidades Con rasgos de especificidad nacional y cultural dependerá mucho del uso que de ellas realicen los hablantes y de las políticas educativas y lingüísticas de los gobiernos nacionales y regionales. (CORPAS PASTOR; MENA MARTÍNEZ, 2004, p. 37)
} 
zoonímica. As metáforas zoonímicas são abordadas por Lakoff e Johnson (1980, p.139), que demonstram que elas enriquecem nosso falar cotidiano e nossa maneira de pensar, influenciando as estruturas dos nossos conceitos.

Nesse modelo, os mecanismos mais comuns são a comparação ou a referência direta ao animal. Os animais mais utilizados "servem de trampolim para categorizar, conceitualizar e lexicalizar situações concretas, que depois metafórica ou metonimicamente se tornam configuradoras de situações gerais" (VILELA, 2003, p. 2). Basta observarmos algumas expressões populares para perceber a presença constante dos animais como pano de fundo para a metaforização em expressões em que a metáfora está evidente, como nos seguintes exemplos: fome de leão, teimoso como uma mula, manso como um cordeiro.

Segundo Vilela (2003, p. 4),

Os valores emblemáticos podem variar. Os traços típicos culturais, como projecção antropomórfica e incorporação de crenças, serviram de base aos empregos metafóricos lexicalizados dos lexemas e expressões. Uma leitura sincrónica da língua tentará decompor, desmotivar e remotivar essas expressões, bebendo na fonte figurada ou não. $\mathrm{O}$ antropomorfismo insinua-se, instaura-se na língua, através das chamadas expressões idiomáticas, dos derivados e compostos.

Tendo em vista valores emblemáticos apontados por Vilela, damos a seguir alguns exemplos de influências culturais e antropomórficas apresentadas em algumas unidades fraseológicas com zoônimos (UFz).

1. Os nomes de animais participam na comparação das reações e estados fisiológicos do corpo humano.

\begin{tabular}{|l|l|}
\hline Pegar o boi pelo chifre & to take the bull by the horns \\
Cair do cavalo & to fall flat on one's face \\
Lágrimas de crocodilo & crocodile tears \\
estar bêbado como gambá & to be drunk as a skunk \\
\hline
\end{tabular}

2. Os nomes de animais para referenciação metonímica podem aparecer em algumas UFz para demonstrar estado de ânimo, pensamentos, e faculdades mentais.

\begin{tabular}{|l|l|}
\hline Ter estômago de avestruz & to have a cast-iron stomach \\
Não ter sangue de barata & not to be meek and mild \\
Que bicho te mordeu? & What is eating you? \\
Comer como um boi & to eat like a horse \\
Aí é que a porca torce o rabo & that's is where the shoe pinches \\
\hline
\end{tabular}

3. Os casos práticos das UFs podem combinar o aspecto cultural e convencional às imagens metafóricas zoonímicas como alternativa de expressividade e comunicação no discurso. Em outras palavras, a análise da imagem-base zoomórfica da UF se realiza por meio dos códigos culturais dos povos e utilizam nomes de animais para referenciação metafórica ligada ao falar humano, como raiva, por exemplo.

\begin{tabular}{|l|l|}
\hline Soltar os cachorros & to tell somebody where to get off \\
Ficar uma arara & be a cross bear \\
Cachorro que late não morde & barking dogs do not bite \\
Gato escaldado tem medo de água fria & once bitten, twice shy \\
\hline
\end{tabular}


4. O animal compõe parte da natureza imaginável, retórica e literária do homem; no convívio com os animais, ao referenciá-los, o homem acaba por espelhar-se nele mesmo. Acrescentamos que os nomes de animais estão presentes em UFs que sofrem influência da contação de histórias, de diálogos com personagens de fábulas de origem clássica.

\begin{tabular}{|l|l|}
\hline Ser um bicho de sete cabeças & to make a mountain out of a molehill \\
Ser cavalo-de-Tróia & to be a trojan horse \\
Ser elefante branco & to be a white elephant \\
Ser um (velho) lobo do mar & to be the sea dog/to be an old salt \\
\hline
\end{tabular}

5. Os nomes de animais estão, ainda, presentes em UFs como influência de origem bíblica.

\begin{tabular}{|l|l|}
\hline Lobo em pele de ovelha & a wolf in sheep's clothing \\
A cavalo dado não se olham os dentes & never look a gift horse in the mouth; \\
(Não) lançar pérolas aos porcos & (No) to throw pearls at pigs \\
Ser o bode expiatório & To be the scapegoat \\
\hline
\end{tabular}

Sublinhamos que exemplos, tais como os apresentados, farão parte de um glossário fraseológico, com respectivos verbetes lexicográficos, na direção português-inglês.

\section{CONSIDERAÇÕES FINAIS}

Diante da diversidade cultural entre os povos, a língua, com sua rica fraseologia, é fortemente influenciada por aspectos extralinguísticos que contam um pouco da experiência vivida e acumulada pelos anos e que desembocam em frases feitas sem que se possa afirmar com certeza sua etimologia. Histórias, vivências, comportamentos, aspectos culturais e antropológicos de toda sorte formatam essas expressões populares e fazem delas repositórios vivos de expressividade, ironia e ensinamentos.

As unidades fraseológicas com zoônimos brasileiras, assim como as de qualquer outra língua, comprovam a diversidade cultural e enriquecem o próprio léxico em matizes de toda a espécie. Os universais linguísticos e fraseológicos oriundos de fontes compartilhadas e alimentados por metáforas zoonímicas e por símbolos de toda espécie permitem entender um pouco das culturas neles imbricados; e o tecido fraseológico vai pouco a pouco sendo desvendado pelas frequentes expressões idiomáticas.

Os nomes de animais desempenham papel relevante em nosso léxico e em nossa fraseologia. Dessa forma, comparar os zoomorfismos das línguas pode abrir novos horizontes para a linguística no entendimento da comunicação entre os povos, principalmente em se tratando dos tempos atuais, em que as janelas da internacionalização se têm aberto para todo tipo de influência antropomórfica e cultural.

\section{REFERÊNCIAS}

CASADEI, F. Metafore ed espressioni idiomatiche. Uno studio semantico sull'italiano. Roma: Bulzoni Editore, 1996.

CORPAS PASTOR, G. Manual de fraseología española. Madrid: Gredos, 1996.

CORPAS PASTOR. G. Las lenguas de Europa: Estudios de fraseología, fraseografia y traducción. Granada: Comares, 2000.

CORPAS PASTOR, G.; MENA MARTÍNEZ, F. M. La globalización de la fraseología como convergencia cultural. Letras de Hoje, Porto Alegre, v. 39, n.1, p. 9-43, mar. 2004.

CORPAS PASTOR, G.; ORTIZ ALVAREZ, M. L. Fraseologia e Paremiologia: uma entrevista com Gloria Corpas Pastor. ReVEL, v. 15, n. 29, 2017. Tradução de Ana Carolina Spinelli. Revisão técnica de Gabriel de Ávila Othero. Disponível em: www.revel.inf.br. 
DOBROVOL'SKIJ, D. Phraseological universals: theoretical and applied aspects. In:

KEFER, M.; AUWERA, J. (Eds.) Meaning and Grammar. Cross-linguistic perspectives. Berlin y New York: Mouton de Gruyter, 1992. p. 279-301.

DOBROVOL'SKIJ, D.; PIIRAINEN, E. Symbole in Sprache und Kultur. Studien zur Phraseologie aus kultursemiotischer Perspektive. Bochum, Brockmeyer, 1997.

DOBROVOL'SKIJ, D.; PIIRAINEN, E. Sobre los símbolos: aspectos cognitivos y culturales del lenguaje figurado. In: BERTRAN; DURÁN (Eds.) Trabajos de lexicografía y fraseología contrastivas. Granada: Método Ediciones y Granada Lingvistica, 2000. p. 29-54.

FIRTH, J. R. Personality and language in society. Reprinted in Firth (1957), Papers in Linguistics 19341951. London: Oxford University Press, 1950. p. 177-189.

GLÁSER, R. Phraseologie der englischen Sprache. Tubingen: Max Niemeyer, 1986.

HALL, E. T. Beyond Culture. New York: Doubleday, [1976] 1989.

JOHNSON, M. The body in the mind. The bodily basis of reason and imagination. Chicago/ London: University of Chicago Press, 1987.

KATAN, D. Translating Cultures ( $2^{\text {nd }}$ ed.). Manchester: St. Jerome, 2004.

KRZESZOWSKI, T.P. The axiological aspect of idealized cognitive models. In: J. Tomaszczyk y B. Lwandowska (Eds.), Meaning and Lexicography. Amsterdam: John Benjamins, 1990. p.135-165.

LAKOFF, G.; JOHNSON, M. Metaphors we live by. Chicago y Londres: The University of Chicago Press, 1980.

LAKOFF, G. Women, Fire, and Dangerous Things: What categories reveal about the mind. Chicago and London: University of Chicago Press, 1987.

LAKOFF, G. The Invariance H is abstract reason based on image schemas? Cognitive Linguistics, v. 1, $\mathrm{n}$. 1, p. 39-74, 1990.

MALINOWSKI, B. Argonauts of the Western Pacific. London: Routledge \& Kegan Paul, 1922.

MALINOWSKI, B. The problem of meaning in primitive languages. In: MAYBIN, J. (Ed.), Language and Literacy in Social Practice: A Reader. Avon: Open University Press, 1923, 1994. p. 1-10.

MALINOWSKI, B. Coral Gardens and Their Magic (2 vol.). London: Allen \& Unwin, 1935.

MANCA, E. From phraseology to culture - qualifying adjectives in the language of tourism.

International Journal of Corpus linguistics, v. 13, n. 3, p. 368-385, 2008.

MANCA, E. Teaching English for tourism: A Phraseological and Cultural Approach. Innovation in Methodology and Practice in Language Learning: Experiences and proposals for University Language Centers (Ed.) Christopher Williams. Cambridge Scholars Publishing, p. 184-201, 2015.

NAZARENKO L.; IÑESTA MENA E.M. Zoomorfismos fraseológicos. In: DURÁN; BERTRÁN (Eds.). Léxico y fraseologia. Granada: Método, 1998.

PAMIES, A. Grammatical metaphor and functional idiomaticity. Yearbook of Phraseology. v. 8, n. 1, p. 69-104. Berlin: De Gruyter, 2017.

PIQUER-PIREZ, A.M.; BOERS, F. La lingüística cognitiva y sus aplicaciones a la enseñanza de lenguas extranjeras. In: IBARRETXE-ANTUÑANO, I; CADIERNO, T; CASTAÑEDA CASTRO, A. (Eds.). Lingüística cognitiva y español LE/L2. Reino Unido: Routledge, 2019. p. 52-70.

PIÑEL LÓPEZ, R. El animal en el refrán, reflejo de una cultura. Estudio contrastivo alemán-español. Paremia 8, p. 411-416, 1999.

RABADÁN, R. La traducción en la prensa y la globalización: funciones pragmáticas y formas textuales. III Seminário de tradução científica e técnica en língua portuguesa: "Tradução, tradutores e traição na comunicação social. Problemas ficos da tradução no jornalismo e nos media", FCT: Fundação para Tecnologia, 2000. Disponível em: http://www.nca.pt/premio.traducao/trabalho /seminario2000/rosa. rabadan.htm. Acesso em: 10 maio 2003.

SINCLAIR, J. MCH. Corpus Concordance Collocation. Oxford: Oxford University Press, 1991.

SINCLAIR, J. MCH. The search for units of meaning. Textus, v. 9, n. 1, p. 71-106, 1996.

VILELA, M. Os estereótipos da metáfora animal: comer gato por lebre. Revista da Faculdade de Letras: Línguas e Literaturas. Porto, XX, II, p. 429-446, 2003.

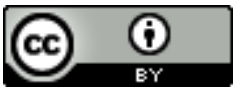

Este texto está licenciado com uma Licença Creative Commons Atribuição 4.0 Internacional. 
